- Additional tables are published online only. To view these files please visit the journal online (http://jech.bmj. com)

${ }^{1}$ Department of Epidemiology and Population Health, London School of Hygiene and Tropical Medicine, London, UK ${ }^{2}$ University of Cambridge, Department of Public Health and Primary Care, Cambridge, UK

\section{Correspondence to}

Dr Caroline Free, Nutrition and Public Health Interventions Department, Department of Epidemiology and Population Health, London School of Hygiene and Tropical Medicine, London WC1E 7HT, UK caroline.free@Ishtm.ac.uk

Accepted 10 May 2009 Published Online First 12 October 2009

\title{
A systematic review of randomised controlled trials of interventions promoting effective condom use
}

\author{
Caroline Free, ${ }^{1}$ lan G Roberts, ${ }^{1}$ Tanya Abramsky, ${ }^{1}$ Molly Fitzgerald, \\ Frances Wensley ${ }^{2}$
}

\section{ABSTRACT}

Background Effective condom use can prevent sexually transmitted infections (STIs) and unwanted pregnancy. We conducted a systematic review and methodological appraisal of randomised controlled trials (RCTs) of interventions to promote effective condom use. Methods We searched for all RCTs of interventions to promote effective condom use using the Cochrane Infectious Diseases Group's trials register (Oct 2006), CENTRAL (Issue 4, 2006), MEDLINE (1966 to 0ct 2006), EMBASE (1974 to Oct 2006), LILACS (1982 to Oct 2006), IBSS (1951 to Oct 2006) and Psychinfo (1996 to 0ct 2006). We extracted data on allocation sequence, allocation concealment, blinding, loss to follow-up and measures of effect. Effect estimates were calculated.

Results We identified 139 trials. Seven out of ten trials reported reductions in 'any STI' with five statistically significant results. Three out of four trials reported reductions in pregnancy, although none was statistically significant. Only four trials met all the quality criteria. Trials reported a median of 11 (IQR 7-17) outcome measures. Few trials used the same outcome measure. Altogether, 10 trials (7\%) used the outcome 'any STI', $4(3 \%)$ self-reported pregnancy and $22(16 \%)$ used 'condom use at last sex'.

Conclusions The results are generally consistent with modest benefits but there is considerable potential for bias due to poor trial quality. Because of the low proportion of trials using the same outcome the potential for bias from selective reporting of outcomes is considerable. Despite the public health importance of increasing condom use there is little reliable evidence on the effectiveness of condom promotion interventions.

\section{INTRODUCTION}

Unsafe sex is believed to be the second most important risk factor for disease, disability or death in the poorest countries of the world, and the ninth most important factor in developed countries. ${ }^{1}$ Effective condom use has the potential to prevent sexually transmitted infections (STIs), including HIV, and unwanted pregnancy. ${ }^{2}{ }^{3}$ However, condom effectiveness is lower than condom efficacy due to non use, inconsistent use and the incorrect application of condoms. ${ }^{4} 5$ Therefore, interventions that promote effective condom use have considerable potential to improve public health.

Interventions to increase effective condom use have addressed condom design, access to condoms, condom use behaviours and condom-related legislation. Existing systematic reviews of the effectiveness of interventions to promote effective condom use have examined specific population groups or interventions, ${ }^{6-8}$ but to date there has been no comprehensive systematic review of randomised controlled trials (RCTs) of interventions to promote effective condom use.

Although systematic reviews of RCTs are considered to provide the most valid and reliable evidence of the effectiveness of healthcare interventions, recent studies have drawn attention to the effect of trial quality and selective publication on their results. ${ }^{9}$ Selective publication of trials has been recognised as a potent threat to validity for many years but more recently the importance of selective publication of trial outcomes has also been highlighted. ${ }^{10-13}$ We report a systematic review and methodological appraisal of RCTs of interventions to promote effective condom use.

\section{METHODS}

\section{Inclusion criteria}

We included all RCTs of interventions to promote effective condom use regardless of publication status or language. Participants were men and women of any age. Interventions were any measure intended to increase effective condom use. Trials of female condoms or those comparing latex and nonlatex condoms were excluded because they have been reviewed previously. ${ }^{14}$ Primary outcomes were the occurrence of pregnancy and STIs. Secondary outcomes were measures of condom use, including condom use at first sexual intercourse, condom use at last sexual intercourse, $100 \%$ condom use, frequency of condom use, frequency of unprotected sex, proportion of episodes of sex protected, condom use scales and refusal of sexual intercourse if condom not used. Secondary outcomes for condom failure outcomes included clinical breakage, non-clinical breakage and full or partial slippage rates.

\section{Search strategy}

We searched the Cochrane Infectious Diseases Group's trials register (Oct 2006), CENTRAL (Issue 4, 2006), MEDLINE (1966 to Oct 2006), EMBASE (1974 to Oct 2006), LILACS (1982 to Oct 2006), IBSS (1951 to Oct 2006) and Psychinfo (1996 to Oct 2006) using the search terms condom, contraceptive devices male, condom breakage, slippage and failure in combination with the Cochrane collaboration's search strategy for retrieving trials (figure 1). ${ }^{15}$ We searched conference proceedings, contacted researchers and organisations working in the field and checked the reference lists of all identified reports. Two reviewers independently scanned the electronic records to identify potentially trials. 
Figure 1 Search strategy.

\begin{tabular}{|c|c|c|c|c|c|}
\hline $\begin{array}{l}\text { Search } \\
\text { set }\end{array}$ & $\begin{array}{l}\text { COCHRANE } \\
\text { CENTRAL }\end{array}$ & MEDLINE & EMBASE & LILACS & IBSS \\
\hline 1 & Condom* ti, ab & Condom* ti, ab & $\begin{array}{l}\text { Condom\$ ti, } \\
\text { ab }\end{array}$ & Condom\$ & Condom* \\
\hline 2 & Condoms [Mesh] & Condoms [Mesh] & $\begin{array}{l}\text { Condom } \\
\text { [Emtree] }\end{array}$ & $\begin{array}{l}\text { Randomized } \\
\text { controlled } \\
\text { trial\$ }\end{array}$ & $\begin{array}{l}\text { Randomized } \\
\text { controlled } \\
\text { trial* }\end{array}$ \\
\hline 3 & $\begin{array}{l}\text { Contraceptive } \\
\text { devices, male [Mesh] }\end{array}$ & $\begin{array}{l}\text { Contraceptive } \\
\text { devices, male [Mesh] }\end{array}$ & 1 or 2 & $\begin{array}{l}\text { Controlled } \\
\text { clinical } \\
\text { trial\$ }\end{array}$ & $\begin{array}{l}\text { Controlled } \\
\text { clinical } \\
\text { trial* }\end{array}$ \\
\hline 4 & 1 or 2 or 3 & 1 or 2 or 3 & $\begin{array}{l}\text { Randomized } \\
\text { controlled } \\
\text { trial\$ }\end{array}$ & Random\$ & Random* \\
\hline 5 & & $\begin{array}{l}\text { Randomized } \\
\text { controlled trial }[\mathrm{pt}]\end{array}$ & $\begin{array}{l}\text { Controlled } \\
\text { clinical trial\$ }\end{array}$ & $\begin{array}{l}\text { (double } \\
\text { blind\$) OR } \\
\text { (single } \\
\text { blind\$) Or } \\
\text { (triple } \\
\text { blind\$) }\end{array}$ & $\begin{array}{l}\text { (double } \\
\text { blind*) OR } \\
\text { (single } \\
\text { blind*) Or } \\
\text { (triple blind) }\end{array}$ \\
\hline 6 & & $\begin{array}{l}\text { Controlled clinical } \\
\text { trial [pt] }\end{array}$ & Random\$ & $\begin{array}{l}\text { Crossover } \\
\text { OR cross- } \\
\text { over }\end{array}$ & $\begin{array}{l}\text { Crossover } \\
\text { OR cross- } \\
\text { over }\end{array}$ \\
\hline 7 & & Random* ti, ab & $\begin{array}{l}\text { (double } \\
\text { blind\$) OR } \\
\text { (single blind\$) } \\
\text { Or (triple } \\
\text { blind\$) }\end{array}$ & $\begin{array}{l}2 \text { or } 3 \text { or } 4 \\
\text { or } 5 \text { or } 6\end{array}$ & $\begin{array}{l}2 \text { or } 3 \text { or } 4 \\
\text { or } 5 \text { or } 6\end{array}$ \\
\hline 8 & & $\begin{array}{l}\text { (double blind*) OR } \\
\text { (single blind*) Or } \\
\text { (triple blind*) ti, ab }\end{array}$ & $\begin{array}{l}\text { Crossover OR } \\
\text { cross-over }\end{array}$ & 1 and 7 & 1 and 7 \\
\hline 9 & & $\begin{array}{l}\text { Crossover OR cross- } \\
\text { over ti, ab }\end{array}$ & $\begin{array}{l}4 \text { or } 5 \text { or } 6 \text { or } 7 \\
\text { or } 8\end{array}$ & & \\
\hline 10 & & 5 or 6 or 7 or 8 or 9 & 3 and 9 & & \\
\hline 11 & & 4 and 10 & $\begin{array}{l}\text { Limit } 10 \text { to } \\
\text { Humans }\end{array}$ & & \\
\hline 12 & & Limit 12 to Human & & & \\
\hline 13 & & & & & \\
\hline
\end{tabular}

We also searched the Cochrane Infectious Diseases Group Specialised register 3 using the term 'condom*'.

\section{Data extraction}

Two reviewers independently extracted data on the generation of the allocation sequence, allocation concealment, blinding and loss to follow-up according to the quality criteria developed by Juni $^{9}$ (see key to additional table 1 online for full details). Overall losses to follow-up of up to $10 \%$ were scored adequate. We extracted data on the measure of effect used in each trial. In trials that collected short and long-term follow-up data, we extracted the long-term follow-up data. A reviewer contacted trial authors asking for all unclear or unreported methods and data. All discrepancies were agreed by discussion with a third reviewer. Trials that scored adequate for reporting of all four quality criteria were categorised as 'high quality trials'. Data were extracted regarding whether clustering had been taken into account in the analysis.

\section{Data analysis and synthesis}

All analyses were conducted in STATA version 9.0. We used funnel plots to explore small study effects. We calculated the log of the ORs and standard mean differences (SMDs). ${ }^{16}$ For the purposes of meta-analysis, condom use outcomes during vaginal sex and unspecified type of sex were treated as the same outcome. Where two or more intervention arms were compared against a single control arm and the arms tested similar interventions, the most intensive intervention (with most components or longest duration) was included in the analysis. Where two or more diverse intervention arms were compared against a single control arm, or a factorial design was used, results are presented separately.

Poor trial quality is a source of bias so we report the results of trials that met the four quality criteria (allocation sequence, allocation concealment, loss to follow-up and blinding of outcome assessment) separately to other trials. We used random effects meta-analysis to give pooled estimates. ${ }^{17}$ Cluster randomised trial effect estimates were calculated based on the intracluster correlation co-efficient reported or, when not reported, the lowest of the published intra cluster co-efficient in the review. ${ }^{18}$ We examined heterogeneity visually by examining forest plots and statistically using the a $\chi^{2}$ test and 12 test for consistency. ${ }^{19}$ We explore the role of study quality via allocation concealment and inadequate or unclear blinding as these elements of study quality have been shown to influence outcomes reported.

\section{RESULTS}

The combined search strategies identified 622 electronic records. These were screened for eligibility and the full texts of 269 potentially eligible reports were obtained for further assessment. Out of the 269 potentially eligible reports, 138 reports containing 139 RCTs met the study inclusion criteria (figure 2). See additional table 1 online for a short description of all studies and the results of the quality assessment. 
Figure 2 Associations of the effects of behavioural interventions on primary outcomes sexually transmitted infection (STI) and self-reported pregnancy. a

Study



b

Study

Odds ratio $(95 \% \mathrm{Cl})$

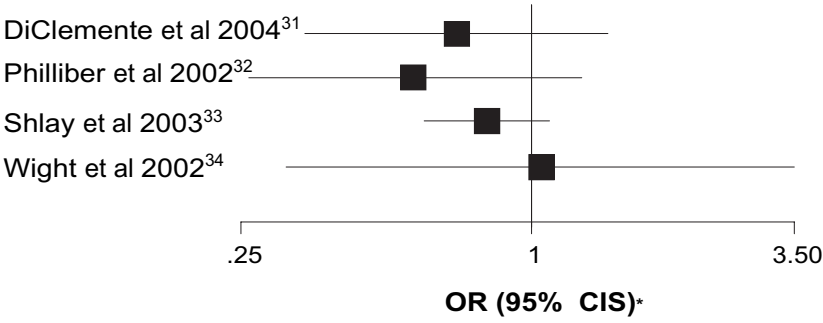

$0.70(0.34,1.44)$

$0.57(0.26,1.27)$

$0.81(0.60,1.09)$

$1.05(0.31,3.50)$

A. Outcome: any STI. B. Outcome: self-reported pregnancy.

*Studies are coded such that an increased OR depicts an increased risk of outcome.

$I^{2}$ values for variation in ORs attributable to heterogeneity were $64 \%$ for STI outcomes and $0 \%$ for self-reported pregnancy.

\section{Characteristics of studies}

The 139 trials included approximately 143000 participants. Of the 139 trials, one used a crossover design, 32 were cluster randomised trials and one used a factorial design. Altogether, 21 of the 32 cluster randomised trials reported having adjusted the results for clustering. Trial participants were recruited from several different settings, including healthcare (57 trials), education (28 trials), community (43 trials), military (1 trial) and unspecified (10 trials). Thirty-three trials had two or more intervention arms. The target populations were young people (48 trials), people with an STI (26 trials), intravenous drug users (19 trials), men who have sex with men (15 trials), other high risk individuals (17 trials), psychiatric patients (5 trials) and unspecified (15 trials). Altogether, 13 trials recruited participants from specific ethnic groups; the other 126 trials did not specify the ethnicity of participants. The median interval between randomisation and last outcome measurement was 26 weeks (IOR 13-52).

\section{Interventions}

The trials evaluated 181 different interventions. These were individual sexual behaviour change $(n=156)$, sexual and intravenous drug behavioural change $(\mathrm{n}=19)$ and condom design $(\mathrm{n}=6)$. There were 23 simple interventions (with one or two components) and 158 complex interventions (with three or more components). The sexual behaviour change interventions addressed information, attitudes, condom use skills and/or condom availability, interpersonal factors within the sexual relationship influencing condom use and social factors influencing sex and condom use (see additional table 2 online). Sexual and intravenous drug behaviour interventions addressed safer injecting behaviour (15 trials), links between substance use and condom use (11 trials), substance use reduction (12 trials) and detoxification treatment $(1$ trial). Condom design trial interventions included providing a choice of condoms of different designs, different standards for manufacture of condoms, thicker/thinner condoms and different shapes of condom (baggy/straight shafted).

\section{Outcomes and reporting bias}

The trials included 90 different STI, pregnancy or condom use outcome measures. Trials reported between 1 and 49 outcomes per trial (median 11; IOR 7-17). Among the outcome measures used most frequently, 10 trials (7\%) used the outcome 'any STI', $4(3 \%)$ self-reported pregnancy and $22(16 \%)$ used 'condom use at last sex'.

Few trials used objective measures. Only 21(15\%) trials reported a pregnancy or objective STI outcome measure. One trial used an objective measure of condom use.

Fifty-two trials did not provide enough data to calculate effect estimates so it was only possible to calculate effect estimates for $63 \%(n=87)$ of the trials. 
Condom use at last vaginal (or unspecified) sex

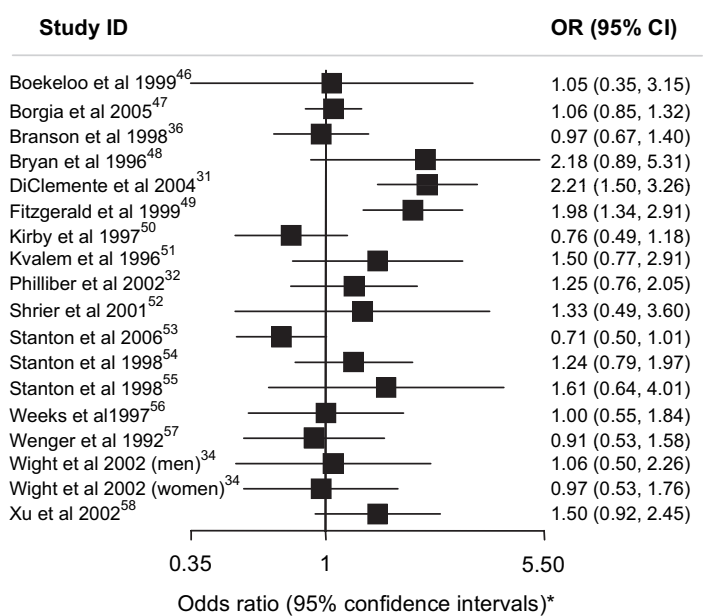

$100 \%$ condom use during anal sex

Study ID

OR $(95 \% \mathrm{Cl})$

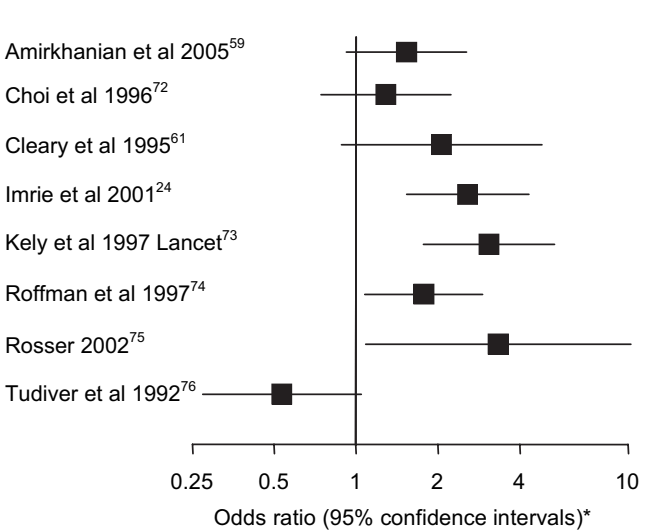

$1.53(0.92,2.55)$

$1.29(0.74,2.23)$

$2.06(0.88,4.81)$

$2.58(1.53,4.32)$

$3.08(1.77,5.37)$

$1.77(1.08,2.92)$

$3.33(1.09,10.24)$

$0.53(0.27,1.04)$

Odds ratio $\left(95 \%\right.$ confidence intervals) ${ }^{\star}$

*Studies are coded such that an increased OR depicts an increased occurrence of protected sex implying a positive outcome from the intervention. $I^{2}$ values for variation in ORs attributable to heterogeneity were $53 \%$ condom use at last sex, $35.5 \%$ for $100 \%$ condom use, $66.8 \%$ for $100 \%$ condom use during anal sex and $0 \%$ for $100 \%$ condom use or abstinence.

Figure 3 Associations of the effects of behavioural interventions on secondary binary outcomes measuring condom use during sex.

\section{Study quality}

Only four trials scored adequate for reporting of all four quality criteria (allocation sequence, allocation concealment, loss to follow-up and blinding). ${ }^{31}$ 35-37 The generation of the allocation sequence was adequate in 54 trials (39\%), allocation concealment was adequate in 32 trials (23\%), losses to follow-up were adequate in 24 trials $(17 \%)$ and outcome assessment was blinded in 34 trials (24\%).

\section{Effectiveness}

For each type of intervention-sexual behaviour change interventions, sexual and intravenous drug behaviour change interventions and condom design interventions-we report the primary (pregnancy and STI) and secondary (condom use) outcomes. The results of high-quality trials are presented first followed by the results of other trials.

\section{Sexual behaviour change interventions}

Primary outcomes: pregnancy and STI

High-quality trial results. There was one trial which met all four quality criteria. Feldblum et al's trial evaluated peer education combined with individual risk counselling by a clinician among
$100 \%$ condom use during vaginal (or unspecified) sex

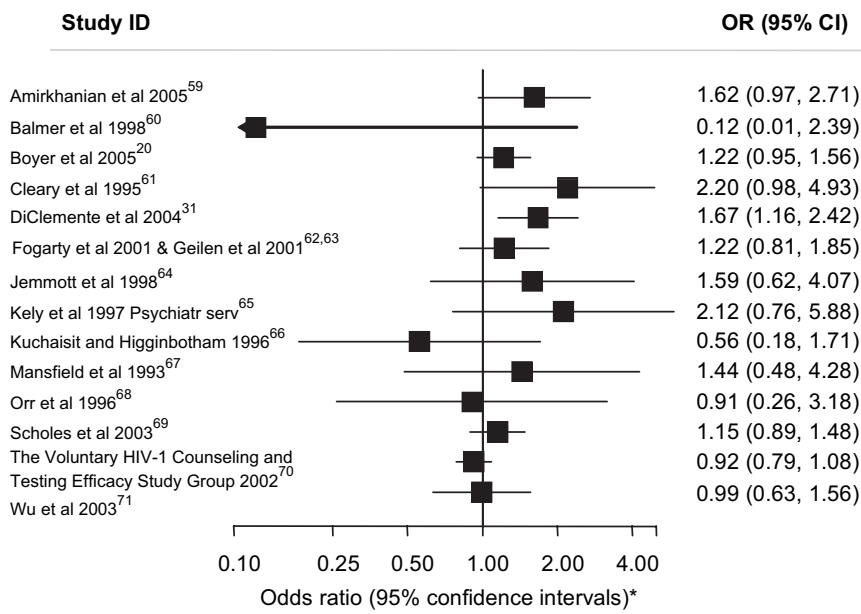

$100 \%$ condom use during vaginal (or unspecified) sex or abstinence

$$
\text { Study ID }
$$

OR $(95 \% \mathrm{Cl})$

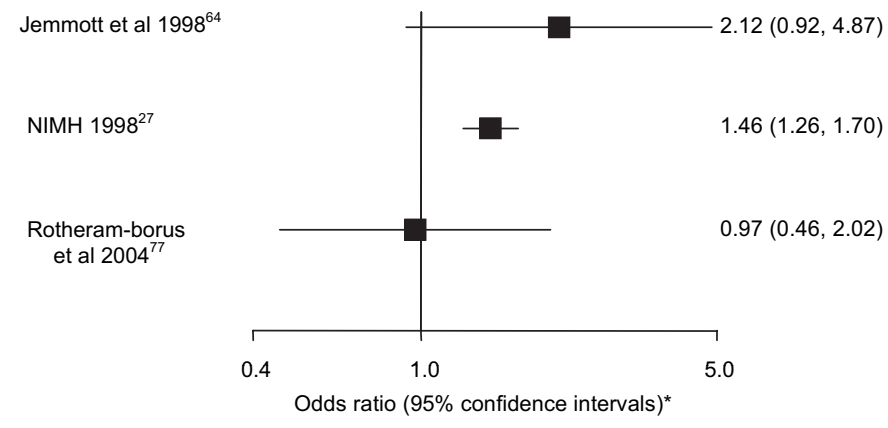
sex workers in Madagascar and reported a reduction in selfreported sexually transmitted disease symptoms $\mathrm{OR}=0.67$ $(0.51-0.89){ }^{35}$

Other trial results. Figure 3 shows forest plots for the effect of complex sexual behaviour change interventions on primary outcome measures. Three of the four trials reporting results regarding self-reported pregnancy had fewer pregnancies in the intervention group but no results were statistically significant. In 7 of the 10 trials reporting the outcome 'any STI' there were fewer STIs in the intervention group with five statistically significant results. One trial reported a statistically significant increase in 'any STI'. Table 1 shows the effect estimates for trials reporting other STI outcomes. In 10 out of the 16 reported outcomes there were fewer STIs in the intervention group with three statistically significant results. One trial reported a statistically significant reduction in gonorrhoea and a statistically significant increase in syphilis. ${ }^{42}$

Exploring heterogeneity in STI outcomes according to study quality. Pooled estimates for the outcome 'any STI' 0.79 (95\% CI 0.66 to $0.94)$ showed considerable heterogeneity $\left(\mathrm{I}^{2} 64 \%, \mathrm{p}=0.003\right)$. The pooled OR for 'any STI' among trials with adequate allocation 
Table 1 Primary outcomes for sexual behaviour change interventions

\begin{tabular}{|c|c|c|}
\hline Study & Outcome & $\begin{array}{l}\text { OR/RR/SMD } \\
\text { (95\% CI) }\end{array}$ \\
\hline \multicolumn{3}{|l|}{ High-quality trials } \\
\hline Feldblum ${ }^{35}$ & STD symptoms & OR 0.67 (0.51 to 0.89 ) \\
\hline \multicolumn{3}{|l|}{ Other trials } \\
\hline Branson $^{36}$ & Gonorrhoea & OR 0.92 (0.64 to 1.32 ) \\
\hline Branson ${ }^{36}$ & Syphillis & OR 1.80 (0.61 to 5.32$)$ \\
\hline Branson $^{36}$ & Chlamydia & OR 0.90 (0.60 to 1.36$)$ \\
\hline $\begin{array}{l}\text { Cohen } 1992^{37} \text { (condom } \\
\text { skills) }\end{array}$ & Reinfection with STI & OR $0.57(0.34$ to 0.96$)$ \\
\hline $\begin{array}{l}\text { Cohen } 1992^{37} \\
\text { (condom distribution) }\end{array}$ & Reinfection with STI & OR 0.91 (0.58 to 1.44$)$ \\
\hline $\begin{array}{l}\text { Cohen } 1992^{37} \\
\text { (condom social influences) }\end{array}$ & Reinfection with STI & OR 0.97 (0.60 to 1.56$)$ \\
\hline Diclemente ${ }^{38}$ & Chlamydia & OR $0.17(0.03 \text { to } 0.09)^{*}$ \\
\hline Explore $^{39}$ & HIV & OR 0.79 (0.61 to 1.02$)$ \\
\hline Gollub ${ }^{40}$ & Probable STI & OR 1.09 (0.60 to 1.99$)$ \\
\hline Harvey ${ }^{41}$ & $\begin{array}{l}\text { Treated for STD in last } \\
6 \text { months }\end{array}$ & OR 0.96 (0.74 to 1.23$)$ \\
\hline Kamali $^{42}$ & HIV rate $(\mathrm{PY})$ & RR 1.00 (0.87 to 1.16$)$ \\
\hline Kamali $^{42}$ & Gonorrhoea rate (PY) & RR 0.43 (0.32 to 0.59$)$ \\
\hline Kamali $^{42}$ & Chlamydia rate (PY) & RR 1.06 (0.88 to 1.27$)$ \\
\hline Kamali $^{42}$ & CHSV2 rate (PY) & RR 1.04 (0.93 to 1.17$)$ \\
\hline Kamali $^{42}$ & Active syphilis rate (PY) & RR 7.01 (5.82 to 8.51) \\
\hline Shain $^{43}$ & Chlamydia or gonorrhoea & OR 0.8 (0.55 to 1.16$)$ \\
\hline
\end{tabular}

Results in italics are for studies with factorial design or those where more than one comparison group tested against a single control has been included.

*These are the results reported in the paper, which adjusted for baseline variables and covariates.

PY, per year; STD, sexually transmitted disease; STI, sexually transmitted infection.

concealment was 0.98 (95\% CI 0.64 to $1.52 ; I^{2} 75.9 \%$; $=0.006$ ) and for trials with inadequate or unclear allocation concealment was 0.73 (95\% CI 0.64 to $0.83 ; \mathrm{I}^{2} 9.8 \% ; \mathrm{p}=0.353$ ). The pooled OR for 'any STI' among trials with adequate blinding of the outcome assessor was 0.83 (95\% CI 0.62 to 1.10 ; I ${ }^{2} 73.4 \%$; $\mathrm{p}=0.01)$ and for trials with inadequate or unclear blinding was 0.76 (95\% CI 0.58 to 0.99 ; I $\mathrm{I}^{2} 39.1 \%$; $\mathrm{p}=0.145$ ).

\section{Secondary outcomes: condom use}

High-quality trial results. There were two trials that met all four quality criteria. Egger et al used an objective measure of condom use (finding a used condom in the motel room bin). ${ }^{44}$ They found that giving out condoms and providing condoms in motel rooms used for commercial sex increased condom use compared to having condoms available on request from reception ( $\mathrm{OR}$ $1.32,95 \%$ CI 1.03 to 1.61 and OR $1.31,1.09$ to 1.75 , respectively. In motel rooms used for non-commercial sex, the same strategies also increased condom use for handing out condoms (OR 1.81, $95 \%$ CI 1.14 to 2.81) and for having condoms in motel rooms (OR 1.52, 95\% CI 1.01 to 2.38). Providing health educational materials reduced condom use in commercial sex compared to when health educational materials were not provided (OR 0.89, 95\% CI 0.84 to 0.94). ${ }^{44}$ Ehrhardt et al evaluated small group gender-specific discussion and used self-reported outcomes of either maintaining or improving safe sex (OR 1.64, 95\% CI 0.95 to 2.86$){ }^{45}$

Other trial results. Figures 4 and 5 and table 2 show the effect estimates for trials for each measure of condom use. For condom use at last sex, 9 of the 18 trials reported increases in condom use with two statistically significant results. For $100 \%$ condom use in vaginal (or unspecified) sex, 9 of the 14 trials reported increases in condom use although none was statistically significant. For
$100 \%$ condom use for anal sex, seven of the eight trials reported increases in condom use with three statistically significant results. Two out of three trials reported increases in 100\% condom use or abstinence with one statistically significant result. No trials reported increases in the frequency of protected sex. Three out of six trials reported statistically significant increases in the proportion of sex protected. For outcomes using condom use scales, two out of four trials reported increases in condom use of which one was statistically significant. One of three trials reported a statistically significant increase in the frequency of condom use. In 16 of the 22 other condom use outcomes reported, there was more condom use in the intervention group with eight showing statistical significance (table 2).

Sexual and intravenous drug behaviour change interventions Primary outcomes: pregnancy and STI

High-quality trial results. There were no trials of sexual and intravenous drug behaviour change interventions that met all four quality criteria.

Other trial results. The Iguchi 1996 trial $^{95}$ compared a 90-day drug detoxification programme to a 21-day drug detoxification programme and reported an OR consistent with a reduction in HIV acquisition (OR 0.37, 95\% CI 0.11 to 1.28 ) (table 3).

Secondary outcomes: condom use

High-quality trial results. There were no trials of sexual and intravenous drug behaviour change interventions reporting condom use outcomes that met all four quality criteria.

Other trial results. In 9 of the 13 condom use outcomes reported there was more condom use in the intervention group with three showing statistical significance (table 3).

\section{Condom design interventions}

Primary outcomes: pregnancy and STI

There were no trials of condom design interventions reporting primary (pregnancy or STI) outcomes.

Secondary outcomes: condom use

High-quality trial results. Golombok et al compared thicker condoms to thinner condoms and found that there was no difference in condom failure before or during sex (OR 1.06, 95\% CI 0.79 to 1.41 ) (table 4). ${ }^{103}$

Other trial results. The Steiner 2006 trial compared providing participants with a choice of different types of condom to providing one type of condom and reported a OR consistent with an increase in acquisition of 'any STI' (OR 1.31, 95\% CI 0.80 to 2.15) for the 'choice of condom' arm. ${ }^{104}$ The Benton 1997 trial $^{105}$ reported that Swiss quality seal standard condoms were less likely to break during anal sex than Australian standard condoms, and the Renzi 2003 trial $^{106}$ of the reality female condom for anal sex reported this was less likely to slip during anal sex than a standard condom (table 4).

\section{DISCUSSION}

\section{Summary of findings}

This review included over 143000 study participants from 139 trials promoting effective condom use. Despite these research efforts, this review cannot provide reliable estimates of the effectiveness of interventions in promoting condom use due to the high potential for bias in the effect estimates. 
Proportion of protected sex

Study ID SMD $(95 \% \mathrm{Cl})$

$0.30(-0.77,0.16)$ $0.04(-0.30,0.21)$

$-0.20(-0.38,-0.02)$

$0.01(-0.16,0.19)$

$0.14(-0.57,0.30)$

$-0.13(-0.41,0.16)$

$-0.12(-0.20,-0.05)$

$-0.03(-0.56,0.50)$

$-0.08(-0.29,0.13)$

$-0.32(-1.21,0.57)$ Weinhardt et al $1998^{84}$

Study ID

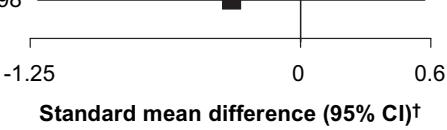

SMD $(95 \% \mathrm{CI})$

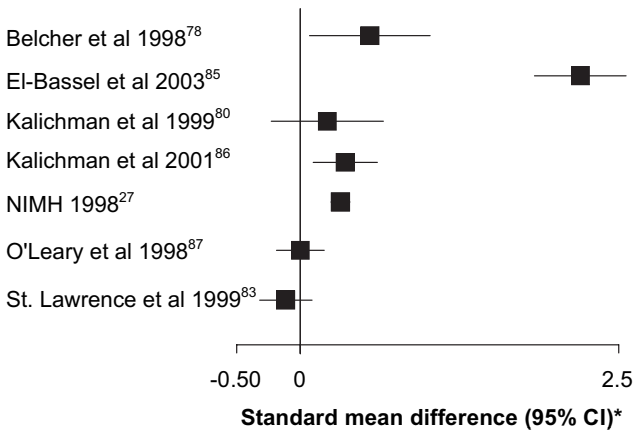

$0.55(0.08,1.02)$

$2.20(1.84,2.56)$

$0.21(-0.23,0.65)$

$0.35(0.10,0.60)$

$0.32(0.24,0.39)$

$0.00(-0.19,0.19)$

$-0.11(-0.32,0.09)$

Standard mean difference $(95 \% \mathrm{CI})^{\star}$

Frequency of condom use

Study ID

SMD $(95 \% \mathrm{Cl})$

Study ID

SMD $(95 \% \mathrm{CI})$

$0.23(-0.11,0.58)$

$0.59(0.38,0.79)$

Jemmott et al $1998^{64}$

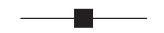

$0.01(-0.35,0.37)$

Wight et al 2002 (men) $^{34}$

$-0.05(-0.35,0.25)$

Wight et al 2002 (women) ${ }^{34}$



* Studies are coded such that an increased standard mean difference depicts an increased use of protective measures related to sexual behaviours as a result of the intervention. $\dagger$ Study coded such that an increased standard mean difference depicts an increased frequency of unprotected sex as a result of the intervention.

$I^{2}$ values for variation in SMD attributable to heterogeneity were $0 \%$ for frequency of unprotected sex, $95.5 \%$ for proportion of unprotected sex, $80.7 \%$ for condom use scales and

$95.1 \%$ for frequency of condom use.

Figure 4 Associations of the effects of behavioural interventions on continuous secondary outcomes looking at frequency or proportion of unprotected sex or condom use.

The potential for bias is high for three main reasons. First, trials were of low quality and only four trials met all the quality criteria. Effect estimates have been found to be higher in lower quality studies where there is no allocation concealment and the results of our subgroup analysis according to allocation concealment are consistent with this. ${ }^{9}$ Second, most trials relied only on self-reported condom use outcomes (85\%). Only one of the trials meeting all four quality criteria also used an objective outcome measure. Third, a low proportion of trials reported data using the same outcomes measure. Among the most commonly used outcomes, only 10 trials (7\%) reported data regarding the outcome 'any STI', 4 (3\%) reported outcome data for pregnancy and $22(16 \%)$ reported outcome data for 'condom use at last sex'. This is likely to have resulted in an overestimate of effects due to selective reporting of outcomes where statistically significant benefit is found. Thus, while the results reported in the trials in this review are generally consistent with modest benefits, the effect estimates cannot be considered reliable.

In the entire review there was only one trial that met all the quality criteria and used a single objective condom use outcome measure. ${ }^{35}$ Furthermore, the intervention was unique and, thus, there is no potential for selective reporting of outcomes in other similar trials. This trial demonstrated that either giving condoms to clients in motels or providing them in motel rooms was effective in increasing condom use for commercial and non-commercial sex.

\section{Strengths and limitations of the review}

This is the first comprehensive systematic review and methodological appraisal of all interventions promoting effective condom use. Descriptions of the intervention components are limited as these were based on the trial reports, which varied considerably in detail. Our analysis of trial quality as a source of heterogeneity, according to blinding and allocation concealment, for the outcome 'any STI' has limited power as few trials contributed to this pooled analysis. The heterogeneity of effect estimates means it is more appropriate to view individual study results; pooled estimates according to study quality are presented to show that these findings are consistent with earlier studies. ${ }^{9}$ We had insufficient power to explore any other aspects of trial quality as sources of heterogeneity. Among the trials reporting an increase in 'any STI', both the Imrie et $\mathrm{al}^{24}$ and Boyer et $a l^{21}$ trials had adequate allocation concealment. Other potential sources of heterogeneity include the type of participants and features of the intervention such as the duration, components and educational media used in the interventions. For example, among the trials reporting an increase in 'any STI', Imrie et al recruited men who defined themselves as 'gay' 24 and Carey et al recruited patients attending outpatient psychiatric care. $^{22}$ Imrie et al's intervention was the only trial that was a single session intervention. ${ }^{24}$ Many of the components addressed in trials of interventions reporting increases in 'any STI' were similar to those addressed in the interventions reporting beneficial effects (eg, information, attitudes, self- 
Figure 5 Flow chart of systematic review.

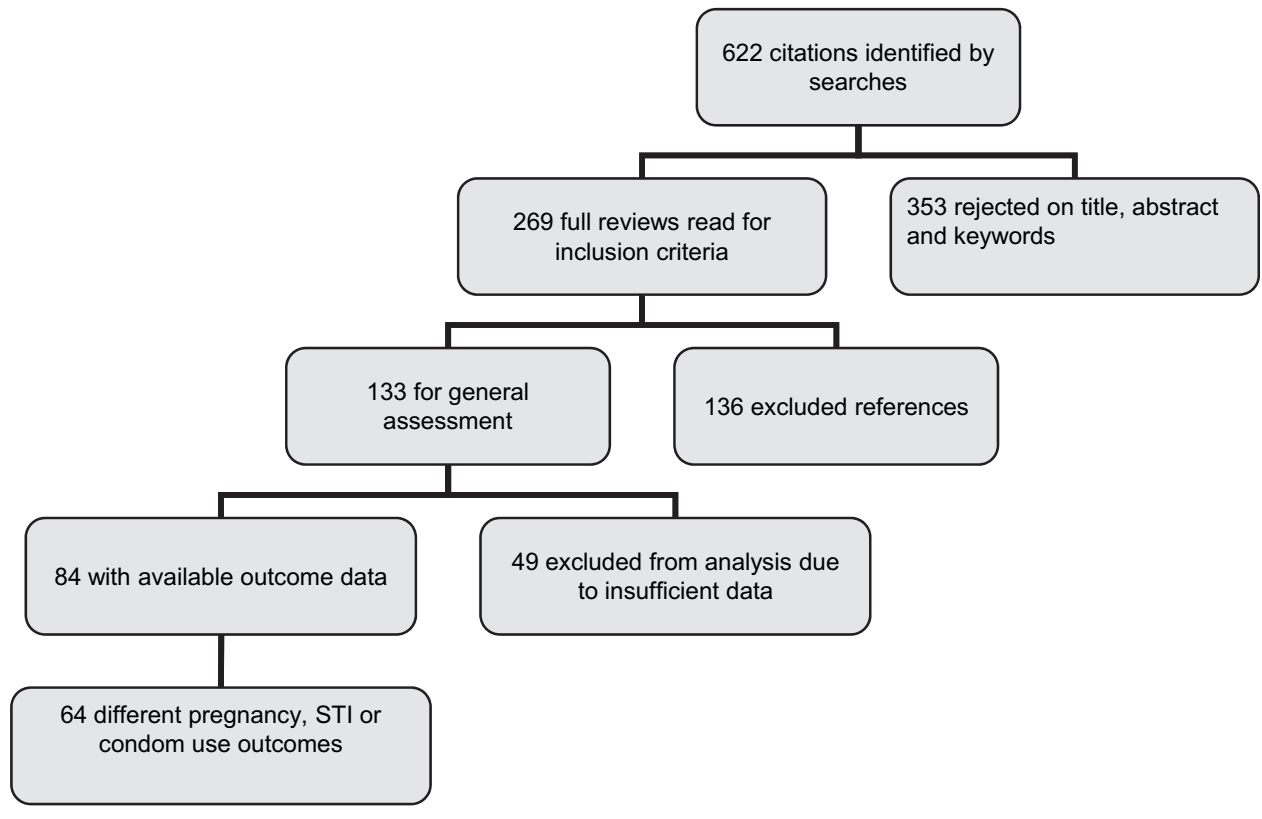

efficacy, condom use skills, condom negotiation skills, motivation), ${ }^{21} 22{ }^{24}$ but Imrie et al's intervention did not involve personal risk assessment, which was addressed by five of the trials reporting beneficial effects. ${ }^{24}$ The interventions also used different educational methods. For example, neither Imrie et al nor Carey et al used videos, which were used in six of the interventions reporting beneficial effects. ${ }^{22}{ }^{24}$ We did not have sufficient power to robustly explore the type of participants and

Table 2 Secondary outcomes for sexual behaviour change interventions

\begin{tabular}{|c|c|c|}
\hline Study & Outcome & OR/SMD (95\% CI) \\
\hline \multicolumn{3}{|l|}{ High quality trials } \\
\hline Egger $^{44}$ (condom in room commercial sex hotel) & Retrieval of at least one condom & OR 1.31 (1.09 to 1.75$)$ \\
\hline Egger $^{44}$ (condom handed to client commercial sex hotel) & Retrieval of at least one condom & OR 1.32 (1.03 to 1.61$)$ \\
\hline Egger $^{44}$ (condom in room, non-commercial sex hotel) & Retrieval of at least one condom & OR 181 (1.14 to 2.81$)$ \\
\hline $\begin{array}{l}\text { Egger }^{44} \text { (condom handed to client non-commercial sex } \\
\text { hotel) }\end{array}$ & Retrieval of at least one condom & OR 1.52 (1.01 to 2.38$)$ \\
\hline Egger $^{44}$ (leaflet, commercial sex workers) & Retrieval of at least one condom & OR $0.89(0.84$ to 0.94$)$ \\
\hline Egger $^{44}$ (leaflet non-commercial sex workers) & Retrieval of at least one condom & OR 1.03 (0.97 to 1.08$)$ \\
\hline Ehrhardt $^{30}$ & Maintaining/improving safe-sex (women) & OR $1.64(0.95$ to 2.86$)$ \\
\hline \multicolumn{3}{|l|}{ Other trials } \\
\hline Bellingham ${ }^{89}$ & Condom use at last sex (vaginal or unspecified) & $\mathrm{OR} 0.58(0.31$ to 1.12$)$ \\
\hline Downs ${ }^{23}$ & Number of condom failures (over period $\geq 3$ months) & SMD $-0.25(-0.55$ to 0.06$)$ \\
\hline Downs ${ }^{23}$ & Consistency of condom use with partners & SMD $0.14(-0.14$ to 0.43$)$ \\
\hline Downs ${ }^{23}$ & Number of condom failures & SMD $-0.25(-0.55$ to 0.06$)$ \\
\hline Hobfoll 88 & Condom use scale (never - always) anal sex & SMD $0.316(-0.034$ to 0.67$)$ \\
\hline Jemmot $^{25}$ & Number of days had unprotected sex in last year & SMD $-4.42(-4.89$ to -3.95$)$ \\
\hline Kalichman ${ }^{80}$ & No condom, no sex (vaginal or unspecified) & OR 1.90 (0.74 to 4.88$)$ \\
\hline Kalichman ${ }^{80}$ & Condom use over $50 \%$ of the time & OR 2.36 (0.92 to 6.01$)$ \\
\hline Picciano $^{90}$ & Frequency of condom use (oral sex) & SMD $0.062(-0.35$ to 0.48$)$ \\
\hline Robert $^{91}$ (eroticising safer sex) & $100 \%$ condom use or abstinence (anal sex) & OR 0.42 (0.10 to 1.89$)$ \\
\hline Robert $^{91}$ (Stop AIDS Programme) & $100 \%$ condom use or abstinence (anal sex) & OR 0.96 (0.18 to 5.22$)$ \\
\hline Roffman $^{74}$ & Proportion of oral sex protected & SMD $0.02(-0.21$ to 0.25$)$ \\
\hline Roffman $^{74}$ & Proportion of anal sex protected & SMD $0.28(0.05$ to 0.52$)$ \\
\hline Rosser $^{75}$ & Change in unsafe anal sex & SMD $-0.20(-0.51$ to 0.11$)$ \\
\hline Rosser $^{75}$ & Change in failure to use condoms & SMD $-0.79(-1.35$ to -0.23$)$ \\
\hline Stephenson ${ }^{92}$ & Unprotected first sex by age 16 y & OR $0.89(0.24$ to 3.31$)$ \\
\hline Shain 1999 and $2002^{29}$ & $<5$ episodes of unsafe sex in last 3 months & OR 2.09 (1.44 to 3.05$)$ \\
\hline Shlay ${ }^{33}$ & Condom use over $50 \%$ of the time & OR $1.14(0.82$ to 1.57$)$ \\
\hline Swanson ${ }^{93}$ & Percentage of time condoms used to prevent herpes & SMD $0.28(0.01$ to 0.54$)$ \\
\hline The Voluntary HIV Testing Study ${ }^{70}$ & $100 \%$ protected sex with non-primary partner & OR 1.32 (0.98 to 1.78$)$ \\
\hline Tripiboon $^{94}$ & Condom use score (for married couples) & SMD 11.04 (10.14 to 11.94$)$ \\
\hline Wenger $^{57}$ & No condom, no sex (unspecified or vaginal) & OR 2.55 (1.19 to 5.45$)$ \\
\hline
\end{tabular}

Results in italics are for trials with a factorial design or trials where the results of more than one comparison group tested against a singe control group are reported. All secondary outcomes reported in this table are used in less than three other trials of this type of intervention. 
Table 3 Primary and secondary outcomes for sexual and intravenous drug behaviour change interventions

\begin{tabular}{|c|c|c|}
\hline Study & Outcome & $\begin{array}{l}\text { OR or SMD } \\
(95 \% \mathrm{CI})\end{array}$ \\
\hline \multicolumn{3}{|l|}{ Primary outcomes } \\
\hline Iguchi $^{95}$ & Acquisition of HIV & OR 0.37 (0.11 to 1.28$)$ \\
\hline \multicolumn{3}{|l|}{ Secondary outcomes } \\
\hline Avants $^{96}$ & Number of weeks had sex without a condom & SMD $-0.326(-0.594$ to -0.059$)$ \\
\hline Cottler $^{97}$ & No sex if no condom & OR $0.99(0.70$ to 1.40$)$ \\
\hline Eldridge ${ }^{98}$ & Log mean proportion of vaginal sex protected & SMD 0.925 (0.356 to 1.494$)$ \\
\hline Kotranski ${ }^{99}$ & $100 \%$ condom use or abstinence (vaginal or unspecified) & OR 1.50 (1.02 to 2.22$)$ \\
\hline Cottler $^{97}$ & $100 \%$ condom use (vaginal or unspecified) & OR 0.95 (0.66 to 1.37$)$ \\
\hline Margolin 100 & $100 \%$ condom use (vaginal or unspecified) & OR 3.94 (0.94 to 16.58$)$ \\
\hline Hershberger ${ }^{101}$ & $100 \%$ condom use (vaginal or unspecified) & OR 2.43 (1.37 to 4.32$)$ \\
\hline Sorensen $^{102}$ (detoxification group) & Proportion of sex protected (vaginal or unspecified) & SMD $0.031(-0.737$ to 0.800$)$ \\
\hline
\end{tabular}

the duration, components and educational media used in the interventions as sources of heterogeneity in this systematic review.

\section{Sources of bias in the systematic review}

First, low trial quality in this review is an important potential source of bias. Effect estimates have been found to be higher where there is no allocation concealment and the results of our subgroup analysis according to allocation concealment are consistent with this. ${ }^{9}$ Second, the use of self-reported condom use outcomes is likely to have resulted in bias. Interventions promoting sexual behaviour change may influence reporting regarding behaviour more than actual behaviour and where participants are not blind to the intervention there may be

Table 4 Primary and secondary outcomes for condom design interventions

\begin{tabular}{|c|c|c|c|}
\hline Study & Type of intervention & Outcome & $\begin{array}{l}\text { OR } \\
(95 \% \mathrm{CI})\end{array}$ \\
\hline \multicolumn{4}{|l|}{ High quality trials } \\
\hline Golombok $^{103}$ & Thicker vs thinner condom & Condom failure before/during sex & OR 1.06 (0.79 to 1.41$)$ \\
\hline Golombok $^{103}$ & Thicker vs thinner condom & Condom failure during sex & OR 1.01 (0.70 to 1.47$)$ \\
\hline Golombok $^{103}$ & Thicker vs thinner condom & Condom breakage before or during sex & OR 1.02 (0.66 to 1.58$)$ \\
\hline Golombok $^{103}$ & Thicker vs thinner condom & $\begin{array}{l}\text { Condom breakage during sex (over } \\
\text { specified time period) }\end{array}$ & OR $0.94(0.49$ to 1.80$)$ \\
\hline Golombok $^{103}$ & Thicker vs thinner condom & Full slippage during sex & OR 1.01 (0.70 to 1.47$)$ \\
\hline Golombok $^{103}$ & Thicker vs thinner condom & Partial slippage during sex & OR $1.06(0.64$ to 1.76$)$ \\
\hline \multicolumn{4}{|l|}{ Other trials } \\
\hline \multicolumn{4}{|l|}{ Primary outcomes } \\
\hline Steiner ${ }^{104}$ & Choice of condoms & Any STI & OR $1.31(0.80$ to 2.15$)$ \\
\hline \multicolumn{4}{|l|}{ Secondary condom use outcomes } \\
\hline $\begin{array}{l}\text { Joanis (C Joanis, M Weaver, C Toroitich- } \\
\text { Ruto, et al, unpublished) }\end{array}$ & Choice of condoms & Proportion of sex protected & SMD $-0.135(-0.250$ to -0.020$)$ \\
\hline Steiner ${ }^{104}$ & Choice of condom & Proportion of sex protected & SMD $0.110(-0.082$ to 0.303$)$ \\
\hline Benton ${ }^{105}$ & $\begin{array}{l}\text { Swiss quality seal: Australian standard } \\
\text { condom }\end{array}$ & Condom breakage during sex & OR 0.86 (0.49 to 1.49$)$ \\
\hline Benton $^{105}$ & $\begin{array}{l}\text { Swiss quality seal: Australian standard } \\
\text { condom }\end{array}$ & Condom breakage during vaginal sex & OR 1.37 (0.65 to 2.89$)$ \\
\hline Benton $^{105}$ & $\begin{array}{l}\text { Swiss quality seal: Australian standard } \\
\text { condom }\end{array}$ & Condom breakage during anal sex & OR $0.20(0.04$ to 0.92$)$ \\
\hline Renzi $^{106}$ & Baggy condom: straight shafted condom & $\begin{array}{l}\text { Condom breakage during sex (over } \\
\text { specified time period) }\end{array}$ & OR 1.34 (0.46 to 3.89$)$ \\
\hline Renzi ${ }^{106}$ & Baggy condom: straight shafted condom & Slippage during sex & OR $0.85(0.57$ to 1.26$)$ \\
\hline Renzi $^{106}$ & Female reality condom for anal sex & $\begin{array}{l}\text { Breakage reported by men (receptive } \\
\text { partners) }\end{array}$ & OR $1.71(0.74$ to 3.96$)$ \\
\hline Macaluso $^{107}$ & Female reality condom for anal sex & $\begin{array}{l}\text { Slippage reported by men (receptive } \\
\text { partners) }\end{array}$ & OR 2.68 (1.92 to 3.75$)$ \\
\hline Macaluso ${ }^{107}$ & Female reality condom for anal sex & $\begin{array}{l}\text { Slippage reported by men (insertive } \\
\text { partner) }\end{array}$ & OR 34.10 (18.97 to 61.27$)$ \\
\hline
\end{tabular}


differential misreporting of outcomes between the intervention and control group. Third, a low proportion of trials reported sufficient data to calculate effect estimates using the same outcome measures. Of the most commonly reported outcomes, only ten trials $(10 \%)$ reported data regarding the outcome 'any STI', four (4\%) reported the outcome 'pregnancy' and $22(16 \%)$ reported condom use at last sex outcomes. Furukawa et al conducted an analysis of Cochrane reviews in which a median of $46 \%$ of trials (IOR $20-75 \%$ ) reported sufficient data to calculate effect estimates using the same outcome. ${ }^{13}$ They found that in systematic reviews where a low proportion of trials used the same outcomes the effect estimates were higher than in systematic reviews where a high proportion of trials used the same outcomes. This is caused by selective reporting of outcomes in trials where no statistically significant benefit is found. ${ }^{13}$ Therefore, the low proportion of trials using the same outcome measures in this systematic review is likely to have resulted in an over-estimate of effect estimates.

\section{Implications for research}

Standards of conduct and reporting for trials promoting effective condom use must urgently be agreed. Consensus must be reached regarding which outcomes must be included irrespective of other reported outcomes. All future trials must include an objective measure of STI or pregnancy so that the trial results can be meaningfully compared and, where relevant, can contribute to future meta-analyses of objective biological outcomes. The components of interventions should be clearly described within trial reports. Trial protocols must be registered in advance with clearly specified outcomes. Trials promoting effective condom use should follow the existing guidance for the reporting and conduct of RCTS. ${ }^{108}$

\section{Implications for condom promotion interventions}

Condom distribution proximal to the time of sex has been shown to increase condom use in one high-quality trial in one setting. Innovative alternate means of distributing condoms proximal to the time of sex, especially among high-risk groups,

\section{What is already known}

CONSORT standards for the conduct and reporting of trials are well-established.

\section{What this paper adds}

- Despite the public health importance of increasing condom use, there is little reliable evidence on the effectiveness of condom promotion interventions.

- There is considerable potential for bias in trials of interventions promoting effective condom use due to poor trial quality.

- Because of the low proportion of trials using the same outcome, the potential for bias from selective reporting of outcomes is also considerable.

- Standards of conduct and reporting for trials promoting effective condom use must be agreed and consensus must be reached regarding which outcomes should be reported in all trials irrespective of other reported outcomes. should be evaluated. A high-quality trial of the female reality condom for anal sex should be conducted as results from a lowquality trial suggest the female reality condom may be less likely to slip than a standard condom. Future sexual behaviour change interventions should be based on the content of existing interventions that report beneficial effects. Such interventions should be evaluated by an adequately powered high-quality RCT.

\section{Conclusion}

Increasing effective condom use is of global public health significance. Reported results in the trials in this review are generally consistent with modest benefits, but bias introduced by the poor quality of trials, reliance on self-reported outcomes and selective reporting of outcomes mean that the reported results are likely to be an over-estimate of effects. Robust conclusions regarding the effectiveness of interventions promoting effective condom use cannot be made. Future trials promoting effective condom use must be conducted and reported to the highest standards.

\section{Competing interests None.}

Contributors CF and IR designed the study, reviewed electronic records and wrote the paper with comments from the other authors. CF, MF and FW extracted data and MF wrote to authors for missing or unclear data. CF, FW and TA cleaned and analysed the data.

Provenance and peer review Not commissioned; externally peer reviewed.

\section{REFERENCES}

1. WHO. Global prevalence and incidence of selected curable sexually transmitted infections: overview and estimates. World Health Organization: Geneva, 2001.

2. Alan Guttmacher Institute. Sharing responsibility: women, society and abortion New York: Alan Guttmacher Institute, 1999.

3. UNAIDS. AIDS epidemic update. Geneva: UNAIDS, 2003.

4. Farr G, Gabelnick H, Sturgen K, et al. Contraceptive efficacy and acceptability of the female condom. Am J Public Health 1994;84:1960-4.

5. Spruyt A, Steiner MJ, Joanis C, et al. Identifying condom users at risk for breakage and slippage: findings from three international sites. Am J Public Health 1998;88:239-44.

6. Shepherd J, Weston R, Peersman G, et al. Interventions for encouraging sexual lifestyles and behaviours intended to prevent cervical cancer (Cochrane Review). In: The Cochrane Library, Issue 1. Oxford: Update Software, 2007.

7. Johnson WD, Hedges LV, Diaz RM. Interventions to modify sexual risk behaviors for preventing HIV infection in men who have sex with men (Cochrane Review). In: The Cochrane Library, Issue 1. Oxford: Update Software, 2007.

8. Oakley A, Fullerton D, Holland J. Behavioral interventions for HIV/AIDS prevention. AIDS 1995:9:479-86.

9. Juni $\mathbf{P}$, Altman DG, Egger M. Systematic reviews in health care: assessing the quality of controlled clinical trials. BMJ 2001;323:42-6.

10. Chan AW, Hrobjartsson A, Haahr MT, et al. Empirical evidence for selective reporting of outcomes in randomized trials: comparison of protocols to published articles. JAMA 2004:291:2457-65.

11. Chan AW, Altman DG. Identifying outcome reporting bias in randomized trials on PUBMED: review of publications and survey of authors. BMJ 2005;330:753-6.

12. Williamson PR, Gamble C. Identification and impact of outcome selection bias in meta-analysis. Stat Med 2005;24:1547-61.

13. Furukawa TA, Watanabe N, Omori IM, et al. Association between unreported outcomes and effect size estimates in Cochrane meta-analyses [Letter]. JAMA 2007;297:468-70

14. Barne R, Shey C, Wiysonge U, Kongynyuy E. Female condom for preventing HIV and sexually transmitted infections. Cochrane library 2008. http://onlinelibrary.wiley. com/o/cochrane/clsysrev/articles/CD003652/frame.html.

15. Higgins JPT, Green S, eds. Chapter 6: Searching for studies. Cochrane Handbook for Systematic Reviews of Interventions Version 5.0.2 (updated September 2009). The Cochrane Collaboration, 2009. www.cochrane-handbook.org.

16. Agresti A. An introduction to categorical data analysis. New York, NY: John Wiley \& Sons, 1996

17. Der Simonian R, Laird N. Meta-analysis in clinical trials. Control Clin Trials 1986:7:177-88.

18. Hayes RJ, Alexander ND, Bennett $\mathrm{S}$, et al. Design and analysis issues in cluster-randomized trials of interventions against infectious diseases. Stat Methods Med Res 2000:9:95-116.

19. Higgins JPT, Green S. eds. Chapter 9: Analysing data and undertaking meta-analyses. Cochrane Handbook for Systematic Reviews of Interventions Version 5.0.2 (updated September 2009). The Cochrane Collaboration, 2009. www.cochrane-handbook.org. 
20. Boyer P, Shafer M, Shaffer R, et al. Evaluation of a cognitive-behavioral, group, randomized controlled intervention trial to prevent sexually transmitted infections and unintended pregnancies in young women. Prev Med 2005:40:420-31.

21. Boyer CB, Barrett D, Peterman T, et al. Sexually transmitted disease (STD) and HIV risk in heterosexual adults attending a public STD clinic: evaluation of a randomized controlled behavioral risk-reduction intervention trial. AIDS 1997;11:359-67.

22. Carey MP, Carey KB, Maisto S, et al. Reducing HIV-risk behavior among adults receiving outpatient psychiatric treatment: results from a randomized controlled trial. J Consult Clin Psychol 2004; 72:252-68.

23. Downs J, Murray P, Bruine de Bruin W, et al. Interactive video behavioral intervention to reduce adolescent females' STD risk: a randomized. Soc Sci Med 2004;59:1561-72.

24. Imrie J, Stephenson J, Cowan F, et al. A cognitive behavioural intervention to reduce sexually transmitted infections among gay men: randomised trial. $B M J$ 2001;322:1451-6.

25. Jemmott JB 3rd, Jemmot LS, Braverman $P$, et al. HIV/STD risk reduction interventions for African American and Latino adolescent girls at an adolescent medicine clinic: a randomized controlled trial. Arch Pediatr Adolesc Med 2005;159:440-9.

26. Kamb ML, Fishbein M, Douglas J, et al. Efficacy of risk-reduction counselling to prevent human immunodeficiency virus and sexually transmitted diseases: a randomized controlled trial. Project RESPECT Study Group. JAMA 1998;7:1161-7.

27. NIMH Multisite HIV Prevention Trial Group. The NIMH Multisite HIV Prevention Trial: reducing HIV sexual risk behavior. The National Institute of Mental Health (NIMH) Multisite HIV Prevention Trial Group. Science 1998;280:1889-94.

28. O'Donnell CR, O'Donnell L, Doval A, et al. Reductions in STD infections subsequent to an STD clinic visit. Using video-based patient education to supplement provider interactions. Sex Transm Dis 1998;25:161-8

29. Shain RN, Piper J, Newton E, et al. A randomized, controlled trial of a behavioral intervention to prevent sexually transmitted disease among minority women. $\mathrm{N} \mathrm{Engl}$ J Med 1999;340:93-100

30. Shain RN, Perdue ST, Piper JM, et al. Behaviors changed by intervention are associated with reduced STD recurrence: the importance of context in measurement. Sex Transm Dis 2002;29:520-9.

31. DiClemente R, Wingwood G, Harrington K, et al. Efficacy of an HIV prevention intervention for African American adolescent girls: a randomized controlled trial. JAMA 2004;292:171-9

32. Philliber $\mathbf{S}$, Kaye J, Herrling $\mathbf{S}$, et al. Preventing pregnancy and improving health care access among teenagers: an evaluation of the children's aid society-carrera program. Perspect Sex Reprod Health 2002;34:244-51.

33. Shlay JC, Mayhugh B, Foster M, et al. Initiating contraception in sexually transmitted disease clinic setting: a randomized trial. Am J Obstet Gynecol 2003:189:473-81.

34. Wight D, Raab G, Henderson $\mathrm{M}$, et al. Limits of teacher delivered sex education: interim behavioural outcomes from randomised trial. BMJ 2002;324:435.

35. Feldblum PJ, Hatzell T, Van Damme K, et al. Results of a randomised trial of male condom promotion among Madagascar sex workers. Sex Transm Infect 2005;81:166-73

36. Branson BM, Peterman TA, Cannon $\mathrm{R}$, et al. Group counseling to prevent sexually transmitted disease and HIV: a randomized controlled trial. Sex Transm Dis 1998;25:553-60

37. Cohen D, Dent C, MacKinnon D, et al. Condoms for men, not women. Results of brief promotion programs. Sex Transm Dis 1992;19:189-333.

38. DiClemente R, Wingwood G, Harrington K, et al. Efficacy of an HIV prevention intervention for African American adolescent girls: a randomized controlled trial. JAMA 2004;292:171-9

39. EXPLORE Study Team. Effects of a behavioural intervention to reduce acquisition of HIV infection among men who have sex with men: the EXPLORE randomised controlled study. Lancet 2005;364:41-50.

40. Gollub EL, French $P$, Loundou $A$, et al. A randomized trial of hierarchical counseling in a short, clinic-based intervention to reduce the risk of Sex Transm Dis in women. AIDS 2000;14:1249-55

41. Harvey B, Stuart J, Swan T. Evaluation of a drama-in-education programme to increase AIDS awareness in South African high schools: a randomized community intervention trial. Int J STD AIDS 2000;11:105-11.

42. Kamali A, Quigley M, Nakiyingi J, et al. Syndromic management of sexuallytransmitted infections and behaviour change interventions on transmission of HIV-1 in rural Uganda: a community randomised trial. Lancet 2003;361:645-52.

43. Shain RN, Piper J, Holden A, et al. Prevention of Gonorrhea and Chlamydia through behavioural intervention: results of two-year controlled randomized trial in minority women. Sex Transm Dis 2004:31:401-8.

44. Egger M, Pauw J, Lopatatzidis A, et al. Promotion of condom use in a high-risk setting in Nicaragua: a randomised controlled trial. Lancet 2000;355:2101-5.

45. Ehrhardt AA, Exner T, Hoffman S, et al. A gender-specific HIV/STD risk reduction intervention for women in a health care setting: short- and long-term results of a randomized clinical trial. AIDS Care 2002;14:147-61.

46. Boekeloo B0, Schamus L, Simmens S, et al. A STD/HIV prevention trial among adolescents in managed care. Pediatrics 1999;103:107-15.

47. Borgia P, Marinacci C. Schifano P, et al. Is peer education the best approach for HIV prevention in schools? Findings from a randomized controlled trial. J Adolesc Health 2005:36:508-16
48. Bryan AD, Aiken L, West S. Increasing condom use: evaluation of a theory-based intervention to prevent sexually transmitted diseases in young women. Health Psychol 1996;15:371-82.

49. Fitzgerald AM, Standon B, Terreri N, et al. Use of Western-based HIV risk-reduction interventions targeting adolescents in an African setting. $J$ Adolesc Health 1999:25:52-61.

50. Kirby D, Korpi M, Adivi C, et al. An impact evaluation of project SNAPP: an AIDS and pregnancy prevention middle school program. AIDS Educ Prev 1997;9:44-61.

51. Kvalem IL, Sundet J, Rivo Kl, et al. The effect of sex education on adolescents' use of condoms: applying the Solomon four-group design. Health Educ 0 1996;23:34-47.

52. Shrier LA, Ancheta R, Goodman E, et al. Randomized controlled trial of a safer sex intervention for high-risk adolescent girls. Arch Pediatr Adolesc Med 2001;155:73-9.

53. Stanton B, Harris C, Cottrell L, et al. Trial of an urban adolescent sexual risk-reduction intervention for rural youth: a promising but imperfect fit. $J$ Adolesc Health 2006:38:55.

54. Stanton B, Li X, Ricardo I, et al. A randomized, controlled effectiveness trial of an AIDS prevention program from low-income African-American youths. Arch Pediatr Adolesc Med 1996:150:363-72.

55. Stanton BF, Li X, Kahihuata J, et al. Increased protected sex and abstinence among Namibian youth following a HIV risk-reduction intervention: a randomized, longitudinal study. AIDS 1998:12:2473-80.

56. Weeks K, Levy S, Gordon A, et al. Does parental involvement make a difference? The impact of parent interactive activities on students in a school-based AIDS prevention program. AIDS Educ Prev 1997;9:90-106.

57. Wenger NS, Greenberg JM, Hilborne LH, et al. Effect of HIV antibody testing and AIDS education on communication about HIV risk and sexual behavior. A randomized, controlled trial in college students. Ann Intern Med 1992;117:905-11.

58. Xu J, Jiyao W, Naiqing Z, et al. The effectiveness of an intervention program in the promotion of condom use among sexually transmitted disease patients. Chin J Epidemiol 2002;23:218-20.

59. Amirkhanian Y, Kelly J, Kabakachieva E, et al. A randomised social network HIV prevention trial with young men who have sex with men in Russia and Bulgaria. AIDS 2005;19:1897-905

60. Balmer DH, Gikundi E, Nasio J, et al. A clinical trial of group counselling for changing high-risk sexual behaviour in men. Couns Psychol 0 1998;11:33-43.

61. Cleary $\mathbf{P}$, Van Devanter $N$, Steilen $\mathbf{M}$, et al. A randomized controlled trial of an education and support program for HIV-infected individuals. AIDS

1995;9:1271-78.

62. Fogarty LA, Heilig C, Armstrong K, et al. Long-term effectiveness of a peer-based intervention to promote condom and contraceptive use among HIV-positive and atrisk women. Public Health Rep 2001;116:103-19.

63. Gielen AC, Fogarty L, Armstrong K, et al. Promoting condom use with main partners: A behavioral intervention trial for women. AIDS Behav 2001:5:193-204.

64. Jemmott JB 3rd, Jemmot LS, Fong G. Abstinence and safer sex HIV risk-reduction interventions for African American adolescents: a randomized controlled trial. JAMA 1998;279:1529-36

65. Kelly JA, McAuliffe T, Sikkema K, et al. Reduction in risk behavior among adults with severe mental illness who learned to advocate for HIV prevention. Psychiatr Serv 1997; 48:1283-8.

66. Kuchaisit C, Higginbotham N. An education intervention to increase the use of condoms for the prevention of HIV infection among male factory workers in Khon Kaen. J Clin Epidemiol 1996;49:13S

67. Mansfield CJ, Conroy M, Emans S, et al. A pilot study of AIDS education and counseling of high-risk adolescents in an office setting. J Adolesc Health 1993; 14:115-19.

68. Orr DP, Langefeld C, Katz B, et al. Behavioral intervention to increase condom use among high-risk female adolescents. J Pediatr 1996;128:288-95.

69. Scholes D, McBride C, Grothaus L, et al. A tailored minimal self-help intervention to promote condom use in young women: results from a randomized trial. AIDS 2003;17:1547-56.

70. Anon. The Voluntary HIV-1 Counseling and Testing Efficacy Study Group. Efficacy of voluntary HIV-1 counselling and testing in individuals and couples in Kenya, Tanzania, and Trinidad: a randomised trial. Lancet 2002;356:103-112.

71. Wu Y, Stanton B, Galbraith J, et al. Sustaining and broadening intervention impact: a longitudinal randomized trial of 3 adolescent risk reduction approaches. Pediatrics 2003;111:32-8

72. Choi K, Lew S, Vittinghoff $\mathrm{E}$, et al. The efficacy of brief group counseling in HIV risk reduction among homosexual Asian and Pacific Islander men. AIDS 1996;10:81-7.

73. Kelly JA, Murphy DA, Sikkema KJ, et al. Community and HIV Prevention Research Network. Randomised, controlled, community-level HIV-prevention intervention for sexual-risk behaviour among homosexual men in US cities. Community HIV Prevention Research Collaborative. Lancet 1997:350:1500-5.

74. Roffman RA, Picciano J, Ryan R, et al. HIV-prevention group counseling delivered by telephone: an efficacy trial with gay and bisexual men. AIDS Behav 1997:1:137-54.

75. Rosser BR, Bockting W, Rugg D, et al. A randomized controlled intervention trial of a sexual health approach to long-term HIV risk reduction for men who have sex with men: effects of the intervention on unsafe sexual behaviour. AIDS Edu Prev 2002;14:59-71. 
76. Tudiver F, Myers T, Kurtz R, et al. The talking sex project: Results of a randomized controlled trial of small-group AIDS education for 612 gay and bisexual men. Eval Health Prof 1992;83:26-42.

77. Rotheram-Borus MJ, Swendeman D, Comulada S, et al. Prevention for substance-using HIV-positive young people telephone and in-person delivery. Acquir Immune Defic Syndr 2004;37:S68-77.

78. Belcher L, Kalichman S, Topping M. A randomized trial of a brief HIV risk reduction counseling intervention for women. J Consult Clin Psychol 1998;66:856-61.

79. Greenberg J, Hennessy M, MacGowan R, et al. Modeling intervention efficacy for high-risk women. The WINGS Project. Eval Health Prof 2000;23:123-48.

80. Kalichman SC, Browne-Sperling F, Cherry C. Effectiveness of a video-based motivational skills-uilding HIV risk-reducation intervention for inner-city African American men. J Consult Clin Psychol 1999;67:959-66.

81. Kelly JA, Murphy D, Washingtom C, et al. The effects of HIV/AIDS intervention groups for high-risk women in urban clinics. Am J Public Health 1994;84:1918-22.

82. Sikkema KJ, Winett R, Lombard D. DeveNot Found In Databaselopment and evaluation of an HIV-risk reduction program for female college students. AIDS Educ Prev 1995; 7:145-59

83. St Lawrence JS, Crosby $R$, Belcher $L$, et al. Sexual risk reduction and anger management interventions for incarcerated male adolescents: A randomized controlled trial of two interventions. J Sex Educ Ther 1999;24:9-17.

84. Weinhardt L, Carey M, Carey K, et al. Increasing assertiveness skills to reduce HIV risk among women living with a severe and persistent mental illness. J Consult Clin Psychol 1998;66:680-4.

85. El-Bassel N, Witte SS, Gilbert L, et al. The efficacy of a relationship-based HIV/STD prevention program for heterosexual couples. Am J Public Health 2003;93:963-9.

86. Kalichman SC, Rompa D, Cage M, et al. Effectiveness of an intervention to reduce HIV transmission risks in HIV-positive people. Am J Prev Med 2001;21:84-92.

87. O'Leary A, Ambrose T, Raffaelli M, et al. Effects of an HIV risk reduction project on sexual risk behavior of low-income STD patients. AIDS Educ Prev 1998;10:483-92.

88. Hobfoll S, Jackcon A, Lavin J, et al. Reducing inner-city women's AIDS risk activities: a study of single, pregnant women. Health Psychol 1994;13:397-403.

89. Bellingham K, Gillies P. Evaluation of an AIDS education programme for young adults. J Epidemiol Community Health 1993:47:134-8.

90. Picciano J, Roffman R, Kalichman S, et al. A telephone based brief intervention using motivational enhancement to facilitate HIV risk reduction among MSM: A pilot study. AIDS Behav 2001;5:251-62.

91. Robert B, Rosser S. Evaluation of the efficacy of AIDS education interventions for homosexually active men. Health Educ Res 1990;5:299-308.

92. Stephenson JM, Strange V, Forrest S, et al; RIPPLE study team. Pupil-led sex education in England (RIPPLE study): cluster-randomised intervention trial. Lancet 2004;364:338-46.
93. Swanson JM, Dibble S, Chapman L. Effects of psycho-educational interventions on sexual health risks and psycho-social adaptation in young adults with genital herpes. J Adv Nurs 1999;29:840-51.

94. Tripiboon D. A HIV/AIDS prevention program for married women in rural northern Thailand. Aust J Prim Health 2001;7:83-91.

95. Iguchi MY, Bux D, Lidz V, et al. Changes in HIV risk behavior among injecting drug users: the impact of 21 versus 90 days of methadone detoxification. AIDS 1996;10:1719-28.

96. Avants SK, Usubiaga M, Doebrick C. Targeting HIV-related outcomes with intravenous drug users maintained on methadone: a randomized clinical trial of a harm reduction group therapy. J Subst Abuse Treat 2004;26:67-78.

97. Cottler LB, Compton W, Abdallah A, et al. Peer-delivered interventions reduce HIV risk behaviors among out-of-treatment drug abusers. Public Health Rep 1998;113:31-41.

98. Eldridge GD, St Lawrence J, Little $\mathrm{C}$, et al. Evaluation of the HIV risk reduction intervention for women entering inpatient substance abuse treatment. AIDS Educ Prev 1997;9:62-76.

99. Kotranski L, Semaan S, Collier K, et al. Effectiveness of an HIV risk reduction counseling intervention for out-of-treatment drug users. AIDS Educ Prev 1998;10:19-33.

100. Margolin A, Avants K, Warburton LA, et al. A randomized clinical trial of a manualguided risk reduction intervention for HIV-positive injection drug users. Health Psychol 2003;22:223-8.

101. Hershberger SL, Wood M, Fisher D. A cognitive-behavioral intervention to reduce HIV risk behaviors in crack and injection drug users. AIDS Behav 2003; 7:229-43.

102. Sorensen JL, London J, Heitzmann C, et al. Psychoeducational group approach: HIV risk reduction in drug users. AIDS Edu Prev 1994:6:95-112.

103. Golombok S, Harding R, Sheldon J. An evaluation of a thicker versus a standard condom with gay men. AIDS 2001;15:245-50

104. Steiner MJ, Hylton-Kong T, Figueroa JP, et al. Does a choice of condoms impact sexually transmitted infection incidence? A randomized, controlled trial. Sex Transm Dis 2006;33:31-5

105. Benton KW, Jolley D, Smith A, et al. An actual use comparison of condoms meeting Australian and Swiss standards: results of a double-blind crossover trial. Int J STD AIDS 1997;8:427-31.

106. Renzi C, Tabet S, Stucky J, et al. Safety and acceptability of the reality condom for anal sex among men who have sex with men. AIDS 2003;17:727-31.

107. Macaluso M, Blackwell R, Carr B, et al. Safety and acceptability of a baggy latex condom. Contraception 2000;61:217-23.

108. Begg C, Cho M, Eastwood S, et al. Improving the quality of reporting of randomized controlled trials. The CONSORT statement. JAMA 1996;276:637-9. 